\title{
2010s-16 \\ Welfare Implications of Leadership in a Resource Market Under Bilateral Monopoly
}

\author{
Kenji Fujiwara, Ngo Van Long
}

Série Scientifique
Scientific Series

Montréal

Avril 2010

(C) 2010 Kenji Fujiwara, Ngo Van Long. Tous droits réservés. All rights reserved. Reproduction partielle permise avec citation du document source, incluant la notice ( $)$.

Short sections may be quoted without explicit permission, if full credit, including $@$ notice, is given to the source.
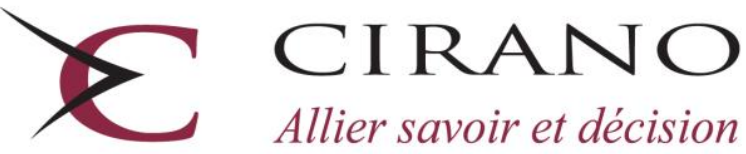

Allier savoir et décision

Centre interuniversitaire de recherche en analyse des organisations 


\section{CIRANO}

Le CIRANO est un organisme sans but lucratif constitué en vertu de la Loi des compagnies du Québec. Le financement de son infrastructure et de ses activités de recherche provient des cotisations de ses organisations-membres, d'une subvention d'infrastructure du Ministère du Développement économique et régional et de la Recherche, de même que des subventions et mandats obtenus par ses équipes de recherche.

CIRANO is a private non-profit organization incorporated under the Québec Companies Act. Its infrastructure and research activities are funded through fees paid by member organizations, an infrastructure grant from the Ministère du Développement économique et régional et de la Recherche, and grants and research mandates obtained by its research teams.

\section{Les partenaires du CIRANO}

Partenaire majeur

Ministère du Développement économique, de l'Innovation et de l'Exportation

\section{Partenaires corporatifs}

Banque de développement du Canada

Banque du Canada

Banque Laurentienne du Canada

Banque Nationale du Canada

Banque Royale du Canada

Banque Scotia

Bell Canada

BMO Groupe financier

Caisse de dépôt et placement du Québec

Fédération des caisses Desjardins du Québec

Gaz Métro

Hydro-Québec

Industrie Canada

Investissements PSP

Ministère des Finances du Québec

Power Corporation du Canada

Raymond Chabot Grant Thornton

Rio Tinto

State Street Global Advisors

Transat A.T.

Ville de Montréal

\section{Partenaires universitaires}

École Polytechnique de Montréal

HEC Montréal

McGill University

Université Concordia

Université de Montréal

Université de Sherbrooke

Université du Québec

Université du Québec à Montréal

Université Laval

Le CIRANO collabore avec de nombreux centres et chaires de recherche universitaires dont on peut consulter la liste sur son site web.

Les cahiers de la série scientifique (CS) visent à rendre accessibles des résultats de recherche effectuée au CIRANO afin de susciter échanges et commentaires. Ces cahiers sont écrits dans le style des publications scientifiques. Les idées et les opinions émises sont sous l'unique responsabilité des auteurs et ne représentent pas nécessairement les positions du CIRANO ou de ses partenaires.

This paper presents research carried out at CIRANO and aims at encouraging discussion and comment. The observations and viewpoints expressed are the sole responsibility of the authors. They do not necessarily represent positions of CIRANO or its partners. 


\title{
Welfare Implications of Leadership in a Resource Market Under Bilateral Monopoly
}

\author{
Kenji Fujiwara ${ }^{*}$, Ngo Van Long ${ }^{\dagger}$
}

\begin{abstract}
Résumé / Abstract
Quand un pays est un leader dans un marché d'une ressource non-renouvelable, est-ce que son niveau de bien-être devient plus élevé? On montre que la réponse est affirmative quand il s'agit d'un leadership global, mais elle peut être négative dans le cas d'un leadership par étapes. Par contre, le niveau de bien-être mondial sous l'équilibre de Nash est supérieur à celui qui est le résultat de l'équilibre global de Stackelberg. Du point de vue du bien-être mondial, l'équilibre de Stackelberg par étapes est meilleur que l'équilibre global de Stackelberg.
\end{abstract}

Mots clés : jeu dynamique, ressources non-renouvelables, leadership de Stackelberg.

Does a country strictly gain if it acts as a leader in a resource market under bilateral monopoly? Using differential games, we show that the answer is "yes" when leadership can be exercised globally (global Stackelberg leadership), but possibly "no" when it is exercised only at each stage (stagewise Stackelberg leadership). On the other hand, world welfare under Nash equilibrium is strictly higher than under global Stackelberg equilibrium. Regardless of which country is the leader, world welfare under stagewise Stackelberg leadership is higher than under global Stackelberg leadership.

Keywords: dynamic game, exhaustible resource, Stackelberg leadership.

Codes JEL : C73, Q34, F18

\footnotetext{
${ }^{*}$ Department of Economics, Kwansai Gakuin University, Japan. Email kenjifujiwara@kwanse.ac.jp ${ }^{\dagger}$ CIRANO and CIREQ, Department of Economics, McGill University, 855 Sherbrooke St West, Montreal, H3A 2T7, Canada. Email: ngo.long@ mcgill.ca Affiliation.
} 


\section{Introduction}

The international distribution of many exhaustible resources is very uneven. For example, $67 \%$ of oil exports come from the OPEC countries while the United States and Japan account for 33\% and 14\% shares of oil imports, respectively. ${ }^{1}$ This suggests the possibility that those countries well endowed with exhaustible resources might seek to take advantage of their position as collective monopolists, and that the resource-deprived countries might seek to exploit their position as collective monopolists. A situation of bilateral monopoly might arise. If one country could secure Stackelberg leadership, would it strictly gains relative to the Nash equilibrium? And would the world as a whole be worse off? Our paper is an attempt to find answers to these questions.

There is a large theoretical literature on the exercise of market power in the trading relationship between a resource-poor economy and a resourcerich economy. Broadly, this literature consists of three groups of models. The first group of models is characterized by the assumption that the resourceexporting country exercises its market power while the importing country is passive. $^{2}$ The second group of models considers the opposite scenario: the importing country imposes a tariff to shift resource rents away from passive foreign resource owners. ${ }^{3}$ The third group of models deals with the case of bilateral monopoly: both the importing country and exporting country realize they have market power and behave strategically. ${ }^{4}$ Our paper belongs to the third group, but we probe more deeply into the issue of leadership.

A useful benchmark equilibrium concept in dynamic games is the feedback Nash equilibrium: each player takes the other player's feedback strategy (i.e. decision rule) as given and chooses a decision rule to maximize its payoff.

\footnotetext{
${ }^{1}$ We have used the 2008 data of the U.S. Energy Information Administration.

${ }^{2}$ See Kemp and Long (1979, Section 4) and a survey by Long (2010).

${ }^{3}$ See Newbery (1976), Kemp and Long (1980), Bergstrom (1982), Brander and Djajic (1983), Karp (1984), Maskin and Newbery (1990), Karp and Newbery (1991, 1992).

${ }^{4}$ This group includes Karp (1984), Wirl (1995), Wirl and Docker (1995), Tahvonen (1996), Rubio and Escriche (2001), Liski and Tahvonen (2004), Rubio (2005), and Chou and Long (2009).
} 
Once a feedback Nash equilibrium has been found, it seems natural to ask whether a player may strictly prefer to be a Stackelberg leader, and if under such a leader-follower game the world's welfare is higher or lower than under the feedback Nash equilibrium. The purpose of our paper is to address these questions and related issues in the context of a resource market under bilateral monopoly.

In dynamic games, there are two main classes of Stackelberg leadership: open-loop Stackelberg leadership, and decision-rule Stackelberg leadership (also called feedback Stackelberg leadership). An open-loop Stackelberg leader announces at the beginning of the game the entire time-path of her actions. In contrast, a decision-rule Stackelberg leader uses a rule which conditions her action at any time on the value of the state variable(s) at that time. Since it has long been established that in general an open-loop Stackelberg equilibrium is time-inconsistent, we will be concerned only with decision-rule Stackelberg leadership. ${ }^{5}$

One of the main contributions of this paper is to distinguish two types of decision-rule Stackelberg leader: stagewise Stackelberg leader and global Stackelberg leader. A stagewise Stackelberg leader is a first-mover at each date (stage); i.e. at each date she is able to commit to an action for that date before the other player moves. In equilibrium, a stagewise Stackelberg leader follows a decision-rule which can be obtained by solving the game backward, beginning with the last date. In contrast, a global Stackelberg leader is committed to a decision rule from the start of the game. To ensure time-consistency, the set of decision rules from which a choice can be made is restricted in such a way that the same decision rule will be chosen by the leader at any feasible (state, date) pair.

To focus on the distinction between these two types of decision-rule Stackelberg leader, we use a simple model of resource extraction for which stagewise Stackelberg leadership has been explored. Various versions of the model

\footnotetext{
${ }^{5}$ See Dockner et al. (2000) for a discussion of the general time-inconsistency of openloop Stackelberg equilibrium, as well as some exceptions. Karp (1984) suggested additional restrictions on the open-loop Stackelberg leader in order to avoid time-inconsistency.
} 
has been studied by Rubio and Escriche (2001), Liski and Tahvonen (2004), Rubio (2005), and Chou and Long (2009). ${ }^{6}$ Rubio and Escriche (2001) and Rubio (2005) restricted their consideration of Stackelberg leadership to the stagewise variety only. They found that if the resource-exporting country is a stagewise Stackelberg leader (i.e. if at each date it can set the producer price before the importing country chooses its tariff rate) the outcome will be identical to the feedback Nash equilibrium. In contrast, we find that if global Stackelberg leadership can be exercised by the resource-exporting country, its payoff will be strictly higher than under the feedback Nash equilibrium. In the case where the resource-importing country is the leader, we find that its payoff as a global leader is strictly higher than its payoff as a stagewise leader (which in turn is strictly higher than its Nash equilibrium payoff).

We are not aware of any paper that compares payoffs under global Stackelberg leadership with payoffs under stagewise Stackelberg leadership, though each of these two leadership concepts has been used in different contexts. For example, Tahvonen (1996), Rubio and Escriche (2001), Benchekroun and Long (2002), and Rubio (2005) restricted attention to stagewise Stackelberg leadership. ${ }^{7}$ An instance of global Stackelberg leadership is Benchekroun and Long (1998) which is reproduced in Dockner et al. (2000, chapter 5) as an example of a time-consistent Markovian Stackelberg equilibrium. ${ }^{8}$

\section{The Model}

There are two countries, a resource-importing country (Home) and a resourceexporting country (Foreign). Foreign does not consume the resource good. Home imposes a specific tariff on its imports. Foreign has a stock of resource $\bar{X}$. The surface area of the mine is unity, so the depth at which the last

\footnotetext{
${ }^{6}$ Liski and Tahvonen (2004) and Chou and Long (2009) considered only the feedback Nash equilibrium.

${ }^{7}$ These authors did not use the expression "stagewise", which made its appearance in Basar et al. (1985) and Mehlmann (1988).

8 For some further considerations of Stackelberg leadership, see Shimomura and Xie (2008) and Long and Sorger (2009).
} 
unit of resource can be found is $\bar{X}$. The marginal cost of extraction increases with the depth of the mine. Let $S$ be the depth reached and $q$ be the rate of extraction, which is the same as the rate at which the depth increases as extraction proceeds: $\dot{S}=q \cdot{ }^{9}$ At any time, the cost of extracting $q$ is $c S q$, i.e., the marginal cost of extraction is $c S$. Thus, the deeper one has to go down, the higher is the marginal cost.

Home's inverse demand function of the resource good is

$$
p^{c}=a-q, \quad a>c,
$$

where $p^{c}$ is the price the consumers have to pay per unit. The parameter $a$ is the 'choke price.' It is the marginal utility of consuming the first unit. Let $\bar{S}$ denote the depth at which the marginal extraction cost equals the choke price, i.e., $c \bar{S}=a$. We assume that $\bar{X}$ is larger than $\bar{S}$. Then, efficiency implies that the resource stock be abandoned at $S=a / c$, i.e., before physical exhaustion of the stock.

Let $\tau$ be a specific tariff rate levied on imported resources. Then, the consumer price is the sum of the producer price $p$ and the tariff rate:

$$
p^{c}=p+\tau
$$

From (1) and (2), the quantity demanded can be expressed as a function of $p$ and $\tau$ as $q=a-p-\tau$, from which the resource dynamics is described by

$$
\dot{S}=a-p-\tau
$$

Chou and Long (2009) solve for a feedback (Markov perfect) Nash equilibrium of a game between Home and Foreign. They assume that Foreign, taking as given Home's feedback tariff rule $\tau=\tau(S)$, chooses a feedback producer price rule $p=p(S)$ to maximize the discounted stream of profit:

$$
\int_{0}^{\infty} e^{-r t} \pi d t=\int_{0}^{\infty} e^{-r t}(p-c S)[a-p-\tau(S)] d t
$$

\footnotetext{
${ }^{9}$ In what follows, we suppress the time argument $t$ unless confusion arises.
} 
Taking Foreign's feedback producer price rule $p=p(S)$ as given, Home chooses a feedback tariff rule $\tau=\tau(S)$ to maximize the discounted stream of the sum of consumer surplus and tariff revenue:

$$
\int_{0}^{\infty} e^{-r t} W d t=\int_{0}^{\infty} e^{-r t} \frac{[a-p(S)+\tau][a-p(S)-\tau]}{2} d t
$$

Assuming that both players simultaneously move, Chou and Long (2009) show that the feedback Nash equilibrium has the following properties:

(i) $p(S)$ is linear affine in $S$ with $p^{\prime}(S)>0$ and $p(\bar{S})=a$

(ii) $\tau(S)$ is linear affine in $S$ with $\tau^{\prime}(S)<0$ and $\tau(\bar{S})=0$,

and (iii) the depth $S(t)$ approaches $\bar{S}$ as $t \rightarrow \infty$.

The feedback Nash equilibrium has an appealing property: as long as marginal cost $c S$ is below the choke price $a$, extraction should proceed. And extraction should never be at a depth where marginal cost $c S$ exceeds the choke price $a$.

The main purpose of our paper is to find feedback Stackelberg equilibria of this game, where the leader is committed to a feedback rule. We consider both the case in which Home leads and the case in which Foreign leads. We begin with the former case, where Home announces in advance to Foreign that it is committed to a feedback tariff rule $\tau(S)$. Clearly, the leader can commit to the Nash equilibrium tariff rule found in Chou and Long (2009), and thus achieve exactly the same outcome in terms of price, quantity, and welfare as in the Nash equilibrium. An interesting question is whether the leader will be able to do strictly better. The next section is devoted to this question. 


\section{Feedback Stackelberg Equilibrium with Im- porter's Leadership}

To find a Stackelberg equilibrium in which Home is a leader, we suppose that it announces right at the beginning of the game a linear feedback tariff rule $\tau(S)=\alpha S+\beta$. Since the game is solved backward, let us consider the follower's problem. Foreign's Hamilton-Jacobi-Bellman (HJB) equation is

$$
r V^{*}(S)=\max _{p}\left\{(p-c S)(a-p-\alpha S-\beta)+V_{S}^{*}(S)(a-p-\alpha S-\beta)\right\},
$$

where $V^{*}(S)$ is Foreign's value function and $V_{S}^{*}(S) \equiv d V^{*}(S) / d S$. The firstorder condition for maximizing the right-hand side yields Foreign's strategy:

$$
p(S)=\frac{V_{S}^{*}(S)+(-\alpha+c) S+a-\beta}{2} .
$$

Given the linear-quadratic structure of the game, it is plausible to guess that $V^{*}(S)$ is quadratic in $S$ :

$$
V^{*}(S)=\frac{A^{*}}{2} S^{2}+B^{*} S+C^{*} \quad \text { for } \quad S \in[0, \bar{S}]
$$

where $A^{*}, B^{*}$ and $C^{*}$ are undetermined coefficients which are endogenously derived below. Equation (6) immediately leads to $V_{S}^{*}(S)=A^{*} S+B^{*}$ and the above strategy is rewritten as

$$
p=\frac{\left(-A^{*}-\alpha+c\right) S-B^{*}+a-\beta}{2} .
$$

Substituting these results into (6), we have an identity in $S$ :

$$
r\left(\frac{A^{*}}{2} S^{2}+B^{*} S+C^{*}\right)=\left[\frac{\left(A^{*}-\alpha-c\right) S+B^{*}+a-\beta}{2}\right]^{2} .
$$

Equating the coefficients of $S^{2}$ and $S$, and of constant term on the left-hand side with those on the right-hand side, we have

$$
\begin{aligned}
\frac{r A^{*}}{2} & =\left(\frac{A^{*}-\alpha-c}{2}\right)^{2} \\
r B^{*} & =\frac{\left(A^{*}-\alpha-c\right)\left(B^{*}+a-\beta\right)}{2} \\
r C^{*} & =\left(\frac{B^{*}+a-\beta}{2}\right)^{2} .
\end{aligned}
$$


Solving the first equation for $A^{*}$ yields

$$
\begin{aligned}
A^{*} & =\alpha+c+r \pm \sqrt{\Delta} \\
\Delta & \equiv r(2 \alpha+2 c+r)>0 .
\end{aligned}
$$

Substituting (7) into the resource dynamics yields $p=\frac{\left(-A^{*}-\alpha+c\right) S-B^{*}+a-\beta}{2}$

$$
\begin{aligned}
\dot{S} & =a-\alpha S-\beta-\frac{\left(-A^{*}-\alpha+c\right) S-B^{*}+a-\beta}{2} \\
& =\frac{\left(A^{*}-\alpha-c\right)}{2} S+\frac{B^{*}+a-\beta}{2} .
\end{aligned}
$$

Therefore, in order to guarantee asymptotic stability, we need to require $\left(A^{*}-\alpha-c\right)<0$. As a result, $A^{*}$ is determined as

$$
A^{*}=\alpha+c+r-\sqrt{\Delta}
$$

Using (8), we obtain

$$
B^{*}=\frac{(-\alpha-c-r+\sqrt{\Delta})(a-\beta)}{\alpha+c} .
$$

Substituting (9) into the equation for $C^{*}$ we get

$$
C^{*}=\frac{1}{4 r}\left[\frac{(-r+\sqrt{\Delta})(a-\beta)}{\alpha+c}\right]^{2} .
$$

Finally, substituting (8) and (9) into (7), the exporting firm's strategy is explicitly derived as

$$
p(S)=\alpha^{*} S+\beta^{*}=\frac{-2 \alpha-r+\sqrt{\Delta}}{2} S+\frac{(2 \alpha+2 c+r-\sqrt{\Delta})(a-\beta)}{2(\alpha+c)} .
$$

Having described the follower's behavior, let us turn to the leader's problem. To this end, substituting (11) into (3), the resource dynamics under linear strategies is

$$
\dot{S}=-\left(\alpha+\alpha^{*}\right) S+a-\beta-\beta^{*},
$$

the solution of which is

$$
S(t)=e^{-\left(\alpha+\alpha^{*}\right) t}\left(S_{0}-\frac{a-\beta-\beta^{*}}{\alpha+\alpha^{*}}\right)+\frac{a-\beta-\beta^{*}}{\alpha+\alpha^{*}} .
$$


The instantaneous welfare of Home under linear strategies $\tau(S)=\alpha S+\beta$ and $p(S)=\alpha^{*} S+\beta^{*}$ is

$$
2 W=\left(\alpha^{* 2}-\alpha^{2}\right) S^{2}-2\left[\alpha \beta+\alpha^{*}\left(a-\beta^{*}\right)\right] S+\left(a-\beta^{* 2}\right)^{2}-\beta^{2} .
$$

Substituting the above solution of $S$, and $\alpha^{*}$ and $\beta^{*}$ into this and rearranging terms, we obtain

$$
\begin{aligned}
2 W= & \frac{r(3 \alpha+c+r)-(2 \alpha+r) \sqrt{\Delta}}{2} e^{(r-\sqrt{\Delta}) t}\left(S_{0}-\frac{a-\beta}{\alpha+c}\right)^{2} \\
& +\frac{(r-\sqrt{\Delta})(\alpha a+\beta c)}{\alpha+c} e^{\frac{r-\sqrt{\Delta}}{2} t}\left(S_{0}-\frac{a-\beta}{\alpha+c}\right)
\end{aligned}
$$

Taking the integral of this function, Home's payoff from any (state, date) pair $\left(S^{\prime}, t^{\prime}\right)$ is function is finally obtained as

$$
\begin{aligned}
\int_{t^{\prime}}^{\infty} e^{-r\left(t-t^{\prime}\right)} 2 W d t= & \frac{r(3 \alpha+c+r)-(2 \alpha+r) \sqrt{\Delta}}{2 \sqrt{\Delta}}\left[S^{\prime}-\frac{a-\beta}{\alpha+c}\right]^{2} \\
& +\frac{2(r-\sqrt{\Delta})(\alpha a+\beta c)}{(r+\sqrt{\Delta})(\alpha+c)}\left[S^{\prime}-\frac{a-\beta}{\alpha+c}\right] .
\end{aligned}
$$

At time $t=0$ Home chooses $\alpha$ and $\beta$ to maximize (12) with $\left(S^{\prime}, t^{\prime}\right)=\left(S_{0}, 0\right)$. Therefore, $\alpha$ and $\beta$ are obtained by solving the first-order conditions by differentiating the right-hand side of (12) -evaluated at $\left(S^{\prime}, t^{\prime}\right)=\left(S_{0}, 0\right)$ with respect to $\alpha$ and $\beta$. However, such solutions for $\alpha$ and $\beta$ would depend on $S_{0}$. This implies that if Home is allowed to reoptimize at any time $t_{1}>0$, the optimal value of $\alpha$ and $\beta$ becomes a function of $S\left(t_{1}\right)$ which is different from $S_{0}$. Accordingly, $\alpha$ and $\beta$ determined at time 0 are no longer optimal at time $t_{1}$, i.e., they are time-inconsistent.

To ensure time-consistency, we impose the restriction that $\alpha a+\beta c=0$. The economic meaning of this restriction is that when $S^{\prime}=\bar{S}$, Home's payoff is zero, as the term inside the square brackets [...] in equation (12) is then zero. $^{10}$

\footnotetext{
${ }^{10}$ We thank Hassan Benchekroun for this observation.
} 
Under this restriction, the above maximization problem amounts to

$$
\max _{\alpha} \frac{r(3 \alpha+c+r)-(2 \alpha+r) \sqrt{\Delta}}{2 \sqrt{\Delta}}\left(S^{\prime}-\frac{a}{c}\right)^{2} .
$$

The first-order condition is

$$
r^{\frac{1}{2}}\left[\frac{3}{2}(2 \alpha+2 c+r)+2 c+\frac{r}{2}\right]=2(2 \alpha+2 c+r)^{\frac{3}{2}} .
$$

While it does not seem possible to obtain an explicit solution of $\alpha$ in this equation, we can prove the existence of the solution. Since we want $\Delta \equiv$ $r(2 \alpha+2 c+r)>0$, let us define $\lambda \equiv 2 \alpha+2 c+r$ and rewrite the above equation as

$$
\frac{3 r^{\frac{1}{2}}}{4} \lambda+\frac{r^{\frac{1}{2}}}{2}\left(2 c+\frac{r}{2}\right)=\lambda^{\frac{3}{2}} .
$$

Squaring both sides, we have

$$
\frac{9 r}{16} \lambda^{2}+\frac{3 r}{4}\left(2 c+\frac{r}{2}\right) \lambda+\frac{r}{4}\left(2 c+\frac{r}{2}\right)^{2}=\lambda^{3} .
$$

Let us define

$$
f(\lambda)=\lambda^{3}-\frac{9 r}{16} \lambda^{2}-\frac{3 r}{4}\left(2 c+\frac{r}{2}\right) \lambda .
$$

The rest of our task is to find $\lambda>0$ that satisfies $f(\lambda)=\frac{r}{4}\left(2 c+\frac{r}{2}\right)^{2}$. The function $f(\lambda)$ has the properties that $f(0)=0$ and $f^{\prime}(0)=-\frac{3 r}{4}\left(2 c+\frac{r}{2}\right)<0$. Noting that $f(-\infty)=-\infty$ and $f(\infty)=\infty$, we conclude that $f(\lambda)=0$ at three values, $\lambda=0, \lambda_{1}<0$, and $\lambda_{2}>0$, and that there exists a unique positive $\lambda^{*}$ which satisfies $f\left(\lambda^{*}\right)=\frac{r}{4}\left(2 c+\frac{r}{2}\right)^{2}$. This implies that there exists a unique value of $\alpha$ which maximizes Home's objective function. Finally, $\beta$ is derived as $\beta=-\alpha a / c$. This result is summarized as follows.

Proposition 1. There exists a unique feedback Stackelberg equilibrium in linear strategies where Home (the importing country) is a leader. As $S$ approaches $\bar{S}$, the tariff rate $\tau$ approaches zero, and the price approaches the choke price a. 


\section{Feedback Stackelberg Equilibrium with Ex- porter's Leadership}

This section turns to the case in which Foreign is a leader. Supposing that Foreign chooses a feedback rule $p(S)=\alpha^{*} S+\beta^{*}$, Home's problem is

$$
\begin{aligned}
\max _{\tau} & \int_{0}^{\infty} e^{-r t} \frac{\left(a-\alpha^{*} S-\beta^{*}+\tau\right)\left(a-\alpha^{*} S-\beta^{*}-\tau\right)}{2} d t \\
\text { s.t. } & \dot{S}=a-\alpha^{*} S-\beta^{*}-\tau .
\end{aligned}
$$

The HJB equation associated with this problem is

$$
\begin{aligned}
r V(S)= & \max _{\tau}\left\{\frac{\left(a-\alpha^{*} S-\beta^{*}+\tau\right)\left(a-\alpha^{*} S-\beta^{*}-\tau\right)}{2}\right. \\
& \left.+V_{S}(S)\left(a-\alpha^{*} S-\beta^{*}-\tau\right)\right\}
\end{aligned}
$$

where $V(S)$ is Home's value function and $V_{S}(S)$ is its derivative with respect to $S$. The first-order condition for maximizing the right-hand side yields

$$
\tau(S)=-V_{S}(S)=-A S-B,
$$

by assuming $V(S)=A S^{2} / 2+B S+C$. Substituting this into the HJB equation, we have an identity in $S$ :

$$
r\left(\frac{A}{2} S^{2}+B S+C\right)=\frac{\left[\left(A-\alpha^{*}\right) S+B+a-\beta^{*}\right]^{2}}{2} .
$$

By applying the procedure developed in the last section, the three parameters are

$$
\begin{aligned}
A & =\frac{2 \alpha^{*}+r-\sqrt{\Gamma}}{2} \\
B & =\frac{-\left(2 \alpha^{*}+r-\sqrt{\Gamma}\right)\left(a-\beta^{*}\right)}{2 \alpha^{*}} \\
C & =\frac{1}{2 r}\left[\frac{(-r+\sqrt{\Gamma})\left(a-\beta^{*}\right)}{2 \alpha^{*}}\right]^{2} \\
\Gamma & \equiv r\left(4 \alpha^{*}+r\right)>0 .
\end{aligned}
$$


Substituting these into (13), the follower's strategy is

$$
\tau(S)=\frac{-2 \alpha^{*}-r+\sqrt{\Gamma}}{2} S+\frac{\left(2 \alpha^{*}+r-\sqrt{\Gamma}\right)\left(a-\beta^{*}\right)}{2 \alpha^{*}} .
$$

Since the dynamics of $S$ is

$$
\dot{S}=a-\alpha^{*} S-\beta^{*}+A S+B,
$$

the solution is obtained as

$$
\begin{aligned}
S(t) & =e^{\left(A-\alpha^{*}\right) t}\left(S_{0}-\frac{a-\beta^{*}+B}{\alpha^{*}-A}\right)+\frac{a-\beta^{*}+B}{\alpha^{*}-A} \\
& =e^{\frac{r-\sqrt{\Gamma}}{2} t}\left(S_{0}-\frac{a-\beta^{*}}{\alpha^{*}}\right)+\frac{a-\beta^{*}}{\alpha^{*}} .
\end{aligned}
$$

Let us now consider the exporting firm's problem. The instantaneous profit is

$$
\pi=(p-c S)(a-p-\tau)=\left(\alpha^{*} S+\beta^{*}-c S\right)\left(a-\alpha^{*} S-\beta^{*}+A S+B\right) .
$$

Substituting $A, B$ and the explicit solution of $S$ into this and making some arrangements yield

$$
\begin{aligned}
\pi= & \frac{\left(\alpha^{*}-c\right)(r-\sqrt{\Gamma})}{2} e^{(r-\sqrt{\Gamma}) t}\left(S_{0}-\frac{a-\beta^{*}}{\alpha^{*}}\right)^{2} \\
& +\frac{\left[a \alpha^{*}-c\left(a-\beta^{*}\right)\right](r-\sqrt{\Gamma})}{2 \alpha^{*}} e^{\frac{r-\sqrt{\Gamma}}{2} t}\left(S_{0}-\frac{a-\beta^{*}}{\alpha^{*}}\right) .
\end{aligned}
$$

Taking the integral at any (state, date) pair $\left(S^{\prime}, t^{\prime}\right)$ we have

$$
\begin{aligned}
2 \int_{t^{\prime}}^{\infty} e^{-r\left(t-t^{\prime}\right)} \pi d t= & \frac{\left(\alpha^{*}-c\right)\left(-4 \alpha^{*}-r+\sqrt{\Gamma}\right)}{4 \alpha^{*}+r}\left(S^{\prime}-\frac{a-\beta^{*}}{\alpha^{*}}\right)^{2} \\
& -\frac{\left[a \alpha^{*}-c\left(a-\beta^{*}\right)\right]\left(2 \alpha^{*}+r-\sqrt{\Gamma}\right)}{\alpha^{* 2}}\left(S^{\prime}-\frac{a-\beta^{*}}{\alpha^{*}}\right) .
\end{aligned}
$$

As was in the last section, let us make the time consistency condition: $a \alpha^{*}-c\left(a-\beta^{*}\right)=0$ under which our problem reduces to

$$
\max _{\alpha^{*}} \frac{\left(\alpha^{*}-c\right)\left(-4 \alpha^{*}-r+\sqrt{\Gamma}\right)}{4 \alpha^{*}+r}\left(S^{\prime}-\frac{a}{c}\right)^{2} .
$$


The first-order condition is

$$
\left(2 \alpha^{*}+2 c+r\right)\left[r\left(4 \alpha^{*}+r\right)\right]^{\frac{1}{2}}=\left(4 \alpha^{*}+r\right)^{2},
$$

which does not yield a close-form expression for $\alpha^{*}$. Fortunately we can prove the unique existence of solution by a transformation of variables.

Let us define $\gamma=4 \alpha^{*}+r$ and square the above equation. Then, we have

$$
r\left(\frac{\gamma}{2}+2 c+\frac{r}{2}\right)^{2} \gamma=\gamma^{4}
$$

which is equivalent to a cubic equation of $\gamma$ :

$$
r\left[\gamma^{2}+(4 c+r)^{2}+2(4 c+r) \gamma\right]=4 \gamma^{3} .
$$

We must find $\gamma>0$ that satisfies this condition. Defining

$$
g(\gamma)=4 \gamma^{3}-r \gamma^{2}-2 r(4 c+r) \gamma
$$

the rest of our task to find a positive $\gamma$ which satisfies $g\left(\gamma^{*}\right)=r(r+4 c)^{2}$.

Since $g(0)=0, g^{\prime}(0)<0, \lim _{\gamma \rightarrow \infty} g(\gamma)=\infty$ and $\lim _{\gamma \rightarrow-\infty} g(\gamma)=-\infty$, we find three solutions to $g(\gamma)=0: \gamma=0, \gamma_{1}<0$ and $\gamma_{2}>0$. Therefore, we have arrived at:

Proposition 2. There exists a unique feedback Stackelberg equilibrium in linear strategies where Foreign (the exporting country) is a leader. As S approaches $\bar{S}$, the tariff rate $\tau$ approaches zero, and the price approaches the choke price a.

\section{$5 \quad$ Feedback Nash Equilibrium}

Having derived two Stackelberg equilibria, we briefly consider the Nash equilibrium. ${ }^{11}$ Chou and Long (2009) show that the feedback Nash equilibrium involves the following pair of the HJB equations.

$$
\begin{aligned}
r V(S) & =\frac{1}{8}\left[a-c S+V_{S}(S)+V_{S}^{*}(S)\right]^{2} \\
r V^{*}(S) & =\frac{1}{4}\left[a-c S+V_{S}(S)+V_{S}^{*}(S)\right]^{2},
\end{aligned}
$$

\footnotetext{
${ }^{11}$ For the details in this section, see Chou and Long (2009).
} 
i.e., $V^{*}(S)=2 V(S)$ and $V_{S}^{*}(S)=2 V_{S}(S)$. Substituting these into Home's HJB equation yields

$$
r V(S)=\frac{1}{8}\left[a-c S+3 V_{S}(S)\right]^{2} .
$$

Let us suppose a quadratic value function $V(S)=A S^{2} / 2+B S+C$. Then, we have

$$
V(S)=\frac{A}{2} S^{2}+B S+C=\frac{\mu^{2}}{8 r} S^{2}-\frac{a \mu^{2}}{4 r c} S+\frac{1}{2 r}\left(\frac{a \mu}{2 c}\right)^{2},
$$

where $\mu=\frac{2}{3}\left[\left(r^{2}+3 c r\right)^{1 / 2}-r\right]$.

Since $V(a / c)=0$, the boundary condition is satisfied. Starting at time zero where $S=0$, the equilibrium welfare of each country is

$$
\begin{aligned}
V(0) & =\frac{1}{2 r}\left(\frac{a \mu}{2 c}\right)^{2} \\
V^{*}(0) & =\frac{1}{r}\left(\frac{a \mu}{2 c}\right)^{2} .
\end{aligned}
$$

Then, the Nash equilibrium strategy pair is

$$
\begin{aligned}
\tau(S) & =\left(\frac{a}{c}-S\right) \frac{\mu^{2}}{4 r} \\
p(S) & =\frac{2 c+\mu}{6} S+\frac{a(r+\mu) \mu}{2 r c} .
\end{aligned}
$$

Note that $\tau(a / c)=0$ and that $p(a / c)=a$. The equilibrium path of accumulated extraction is

$$
S=\frac{a}{c}\left(1-e^{-\frac{\mu t}{2}}\right) .
$$

The equilibrium producer's price path is

$$
p=a\left[1-\left(\frac{2 c+\mu}{6 c}\right) e^{-\frac{\mu t}{2}}\right],
$$

which allows us to know that $p(t)>0$ for all $t$. The equilibrium tariff is

$$
\tau=\frac{\mu^{2}}{4 r}\left(\frac{a}{c}\right) e^{-\frac{\mu t}{2}}
$$

Thus, we can establish:

Proposition 3. There exists a unique feedback Nash equilibrium in linear strategies. As $S$ approaches $\bar{S}$, the tariff rate $\tau$ approaches zero, and the price approaches the choke price a. 


\section{Welfare Implications}

\subsection{Comparing with Nash equilibrium}

We now have three feedback solutions and the corresponding levels of welfare of each country and the world. Our finding is summarized in Tables 1, 3 and $5 .{ }^{12}$ These tables provide us with several interesting observations.

First, the world welfare which is the sum of the two countries' welfare is largest in the Nash equilibrium and lowest in the Stackelberg equilibrium where the importing country is a leader. This result relies crucially on the assumption that the exporting country uses a price decision rule. Might it be reversed once the exporting country's strategy on price (a price decision rule) is replaced by a quantity decision rule? In a companion paper, assuming that the exporting firm uses a quantity decision rule, Fujiwara and Long (2009) show that the Nash equilibrium indeed yields the smallest world welfare compared to either Stackelberg equilibrium; in particular the Stackelberg equilibrium with the importer's leadership yields the largest world welfare. ${ }^{13}$

The second point, which is related to the first one, is that under price strategies the Stackelberg equilibria are not Pareto superior to the Nash equilibrium. In other words, both players' welfare can not improve simultaneously by moving from the Nash equilibrium to either Stackelberg equilibrium. This is again reversed in the quantity setting model of Fujiwara and Long (2009), where in any one of the two Stackelberg equilibria, both players' payoffs are higher than in the Nash equilibrium. That is, when the exporting country determines the output, there is no conflict of interest between countries concerning the movement from Nash to Stackelberg.

\subsection{Comparing with stagewise Stackelberg leadership}

The feedback Stackelberg equilibria we have derived can be called a global (or hierarchical) feedback Stackelberg equilibria since the leader determines its

\footnotetext{
${ }^{12}$ Detailed calculations are available from the authors upon request.

${ }^{13}$ This contrast is analogous to the sharp contrast between the implications of the Brander-Spencer model and those of the Eaton-Grossman model of strategic trade policies.
} 
strategy over the entire horizon, prior to the strategy choice of the follower. On the other hand, a different concept of feedback Stackelberg equilibrium has been used in literature, which has been called a stagewise feedback Stackelberg equilibrium (see Basar and Olsder, 1995, and Mehlmann,1988).

A player is said to be a stagewise Stackelberg leader if at each point of time $t$ she takes her action, say $u_{L}(t)$, before the other player (the follower) chooses his action, say $u_{F}(t)$. The follower's action at time $t$ is a "reaction" to the leader's action $u_{L}(t)$. If time is discrete and the game is a finite-horizon game, backward solution yields the stagewise Stackelberg equilibrium. If time is continuous and/or the time horizon is infinite, an argument relying on taking limits shows that a dynamic-programming based method also applies. ${ }^{14}$

In a framework similar to ours, Rubio and Escriche (2001) characterize the stagewise feedback Stackelberg equilibria and conclude that, when the exporting country leads, the Stackelberg equilibrium is identical to the Nash equilibrium. ${ }^{15}$ This coincidence between a stagewise Stackelberg outcome and the Nash outcome may be explained by depicting a reaction curve diagram of a static version of our model. From (4) and (5), the first-order condition for 'static' maximization of each country is

$$
\begin{aligned}
& \frac{\partial W}{\partial \tau}=-\tau=0 \\
& \frac{\partial \pi}{\partial p}=a-2 p-\tau=0 .
\end{aligned}
$$

Figure 1 depicts the reaction curve diagram, from which it is obvious that the intersection of the two reaction curves gives the Stackelberg equilibrium where Foreign (exporting country) is a leader as well as the Nash equilibrium. Thus, the above finding of Rubio and Escriche (2001) can be regarded as a dynamic extension of this static result: under stagewise leadership of the exporting country, the importing country's optimal tariff rate at time $t$ is not

\footnotetext{
${ }^{14}$ Levhari and Mirman (1980) solved for both the Nash equilibrium and the stagewise Stackelberg equilibrium of a fish-war model in discrete time. Basar et al. (1985) solved for the stagewise Stackelberg equilibrium of a model of capitalist-worker conflict in discrete time and argued that the method can extended to the continuous time setting.

${ }^{15}$ They also find that this is not the case when the importing country leads.
} 
dependent on the price $p(t)$ and thus the exporting country gains nothing from being a stagewise leader ${ }^{16}$.

\section{(Figure 1)}

This subsection shows how stagewise leadership leads to numerical values that are totally different from global leadership.

Assuming quadratic value functions, $V(S)=A S^{2} / 2+B S+C$ and $V^{*}(S)=A^{*} S^{2} / 2+B^{*} S+C^{*}$, the stagewise feedback Stackelberg equilibrium with Home's leadership is obtained as follows. ${ }^{17}$

$$
\begin{aligned}
A & =\frac{27 r+30 c-9 \sqrt{\Psi}}{50} \\
B & =\frac{3(2 r-\sqrt{\Psi})}{5(3 r+\sqrt{\Psi})} \\
C & =\frac{3}{2 r}\left[\frac{(3 r-\sqrt{\Psi}) a}{10 c}\right]^{2} \\
A^{*} & =\frac{2}{3} A, \quad B^{*}=\frac{2}{3} B, \quad C^{*}=\frac{2}{3} C \\
\Psi & =r(9 r+20 c)>0 .
\end{aligned}
$$

Tables 1 and 2 permit comparison of outcomes in terms of welfare under the global Stackelberg solution concept and the stagewise Stackelberg solution concept, respectively, using the same parameter values. ${ }^{18}$ These tables show that the difference between the two solution concepts is striking. In particular, it is worth mentioning that the leader's welfare increment relative to the Nash equilibrium is larger in the global Stackelberg equilibrium (i.e. with its precommitment to a time-consistent Markovian decision rule) than in the stagewise Stackelberg equilibrium (where such a precommitment is ruled out). Similarly, the follower loses more in the global solution than in

\footnotetext{
${ }^{16}$ In contrast, if it is the global leader, it is committed to a pricing strategy $p=\alpha^{*} S+\beta$ and clearly $\tau$ would depend on these parameters.

${ }^{17}$ Derivations are found in Appendix A in Rubio and Escriche (2001).

${ }^{18}$ Tables 3-6 show that exactly the same conclusion holds under other parameter values.
} 
the stagewise solution. This is because the leader can take better advantage of its leadership position in the global solution by precommitting. However, we must note that the leader gains at the expense of the follower's large welfare losses, thereby leading to a decline in the world welfare in Stackelberg equilibria relative to the Nash equilibria. This world welfare losses are larger in the global solution than in the stagewise solution for the above reason. In other words, whether the leader can precommit has significant implications from a practical point of view as well as theoretically.

\section{Concluding Remarks}

We have considered some welfare implications of a dynamic game model of international trade involving exhaustible resource extraction. This paper possibly has contributed to both international economics and dynamic game theory. While we have characterized three feedback solutions in a dynamic trade model with a linear-quadratic structure where both countries exercise market power, our technique of deriving the global Stackelberg solutions through using a time-consistency condition is applicable to a wide variety of dynamic games.

However, our attempt is preliminary, leaving much unexplored. In particular, we have exclusively focused on the linear feedback solutions. As is recently documented by Shimomura and Xie (2008), dynamic Stackelberg games can admit nonlinear strategies which may lead to a superior outcome than linear strategies. ${ }^{19}$ We plan to tackle non-linear strategies in our future research.

\section{References}

[1] Basar, T. and G. Olsder (1995), Dynamic Noncooperative Game Theory, San Diego, Academic Press.

\footnotetext{
${ }^{19}$ Shimomura and Xie (2008) derive a useful 'Implementation Lemma', but their argument assumes the existence of the equilibrium. Further exploration is found in Long and Sorger (2009).
} 
[2] Başar, T., A. Haurie, and G. Ricci (1985), "On the Dominance of Capitalists Leadership in a 'Feedback Stackelberg' Solution of a Differential Game Model of Capitalism," Journal of Economic Dynamics and Control 9: 101-125.

[3] Benchekroun, H. and N. V. Long (1998), Efficiency Inducing Taxation for Polluting Oligopolists, Journal of Public Economics, 70: 325-342.

[4] Benchekroun, H. and N. V. Long (2002), Transboundary Fishery: A Differential Game Model, Economica, 69: 207-221.

[5] Bergstrom, T. C. (1982), On Capturing Oil Rents with A National Excise Tax, American Economic Review 72: 194-201.

[6] Brander, J. and S. Djajic (1983), Rent Extracting Tariffs and the Management of Exhaustible Resources, Canadian Journal of Economics, 16, 288-98.

[7] Chou, S. and N. V. Long (2009), "Optimal Tariffs on Exhaustible Resources in the Presence of Cartel Behavior," Asia-Pacific Journal of Accounting and Economics, 16(3): 239-254.

[8] de Zeeuw, A. J. and F. van der Ploeg (1991), " Difference Games and Policy Evaluation: A Conceptual Framework," Oxford Economic Papers 43: 612-636.

[9] Fujiwara, K. and N. V. Long (2009), "Optimal Tariffs on Exhaustible Resources: the Case of Quantity-Setting," Working Paper, Department of Economics, McGill University.

[10] Karp, L. (1984), "Optimality and Consistency in a Differential Game with Non-Renewable Resources," Journal of Economic Dynamics and Control 8: 73-97.

[11] Karp, L. and D. M. Newbery (1991), "Optimal Tariffs on Exhaustible Resources," Journal of International Economics, Vol. 30(3-4): 285-299. 
[12] Karp, L., and D. M. Newbery (1992), Dynamically Consistent Oil Import Tariffs, Canadian Journal of Economics, 25, 1-21

[13] Kemp, M.C. and N. V. Long (1979), "The Interaction between ResourcePoor and Resource-Rich Economies," Australian Economic Papers 18: 258-267, reprinted as Essay 17 in M. C. Kemp and N. V. Long (Eds.), Exhaustible Resources, Optimality and Trade, 1980, pp.197-209, North Holland, Amsterdam.

[14] Kemp, M. C., N. V. Long and K. Shimomura (2001), "A Differential Game Model of Tariff War," Japan and the World Economy, 13(3): 279298.

[15] Kydland, F. (1975) "Non-cooperative and Dominant Player Solutions in Discrete Dynamic Games," International Economic Review 16: 321-335.

[16] Levhari, D. and L. Mirman (1980), "The Great Fish Wars: An Example of Using a Dynamic Nash-Cournot Solution," Bell Journal of Economics 11:322-34

[17] Liski, M. and O. Tahvonen (2004), "Can Carbon Tax Eat OPEC's Rents?" Journal of Environmental Economics and Management, 47: 112.

[18] Long, N. V. (2010), A Survey of Dynamic Games in Economics, World Scientific (to appear).

[19] Long, N. V. and G. Sorger (2009), "A Dynamic Principal-Agent Problem as a Feedback Stackelberg Differential Game," Working Paper No. 0905, Department of Economics, University of Vienna.

[20] Maskin, E. and D. Newbery (1990), Disadvantageous Oil Tariffs and Dynamic Consistency, American Economic Review 80: 143-156.

[21] Mehlmann, A. (1988), Applied Differential Games, New York, Kluwer Academic Publishers. 
[22] Newbery, D. (1976), "A Paradox in Tax Theory: Optimal Tariffs on Exhaustible Resources," Unpublished manuscript.

[23] Rubio, S. (2005), Tariff Agreements and Non-Renewable Resource International Monopolies: Prices versus Quantity, Working Paper WP-AD2005-10, University of Valencia.

[24] Rubio, Santiago and Luisa Escriche (2001), Strategic Pigouvian Taxation, Stock Externalities and Polluting Non-renewable Resources, Journal of Public Economics 79: 297-313.

[25] Shimomura, K. and D. Xie (2008), "Advances on Stackelberg Open-Loop and Feedback Strategies," International Journal of Economic Theory, Vol. 4(1): 115-133.

[26] Simaan, M. and J. B. Cruz (1973), "Additional Aspects of the Stackelberg Strategy in Non-Zero Sum Games," Journal of Optimization Theory and Applications, 11: 613-626.

[27] Smith, J. L., (2009), "World Oil: Market or Mayhem?," Journal of Economic Perspective, Vol. 23(3): 145-164.

[28] Tahvonen, O. (1996), Trade with Polluting Non-Renewable Resources, Journal of Environmental Econ and Management 30: 1-17Wirl, F. (1994), Pigouvian Taxation of Energy for Flow and Stock Externalities and Strategic, Non-competitive Energy Pricing, Journal of Environmental Economics and Management 26: 1-18.

[29] Wirl, F. (1995), The Exploitation of Fossil Fuels under the Threat of Global Warming and Carbon Taxes: A Dynamic Game Approach, Environmental and Resource Economics 5: 333-352

[30] Wirl, F. and Dockner, E. (1995) Leviathan Governments and Carbon taxes: Costs and Potential Benefits, European Economic Review 39: $1215-1236$ 


\begin{tabular}{|c|c|c|c|}
\hline & Home & Foreign & Total \\
\hline \hline Nash & $0.128831946 a^{2}$ & $0.257663892 a^{2}$ & $0.386495838 a^{2}$ \\
\hline Stackelberg (Home is leader) & $0.275 a^{2}$ & $0.05 a^{2}$ & $0.325 a^{2}$ \\
\hline Stackelberg (Foreign is leader) & $0.042548195 a^{2}$ & $0.307126431 a^{2}$ & $0.349674626 a^{2}$ \\
\hline
\end{tabular}

Table 1: Example 1 (global solution): payoffs under $S_{0}=0, r=0.05$ and $c=1$

\begin{tabular}{|c|c|c|c|}
\hline & Home & Foreign & Total \\
\hline \hline Nash \& Foreign is leader & $0.128831946 a^{2}$ & $0.257663892 a^{2}$ & $0.386495838 a^{2}$ \\
\hline Stackelberg (Home is leader) & $0.222493132 a^{2}$ & $0.148328754 a^{2}$ & $0.370821886 a^{2}$ \\
\hline
\end{tabular}

Table 2: Example 1 (stagewise solution): payoffs under $S_{0}=0, r=0.05$ and $c=1$ 


\begin{tabular}{|c|c|c|c|}
\hline & Home & Foreign & Total \\
\hline \hline Nash & $0.4 a^{2}$ & $0.8 a^{2}$ & $1.2 a^{2}$ \\
\hline Stackelberg (Home is leader) & $0.750340468 a^{2}$ & $0.211085264 a^{2}$ & $0.961425732 a^{2}$ \\
\hline Stackelberg (Foreign is leader) & $0.187621814 a^{2}$ & $0.889234071 a^{2}$ & $1.07685589 a^{2}$ \\
\hline
\end{tabular}

Table 3: Example 2 (global solution): payoffs under $S_{0}=0, r=0.05$ and $c=0.25$

\begin{tabular}{|c|c|c|c|}
\hline & Home & Foreign & Total \\
\hline \hline Nash \& Foreign is leader & $0.4 a^{2}$ & $0.8 a^{2}$ & $1.2 a^{2}$ \\
\hline Stackelberg (Home is leader) & $0.664297931 a^{2}$ & $0.442865287 a^{2}$ & $1.10716322 a^{2}$ \\
\hline
\end{tabular}

Table 4: Example 2 (stagewise solution): payoffs under $S_{0}=0, r=0.05$ and $c=0.25$

\begin{tabular}{|c|c|c|c|}
\hline & Home & Foreign & Total \\
\hline \hline Nash \& Foreign is leader & $0.115913729 a^{2}$ & $0.231827458 a^{2}$ & $0.347741187 a^{2}$ \\
\hline Stackelberg (Home is leader) & $0.232629432 a^{2}$ & $0.052793837 a^{2}$ & $0.285423269 a^{2}$ \\
\hline Stackelberg (Foreign is leader) & $0.045787993 a^{2}$ & $0.266915675 a^{2}$ & $0.312703668 a^{2}$ \\
\hline
\end{tabular}

Table 5: Example 3 (global solution): payoffs under $S_{0}=0, r=0.1$ and $c=1$

\begin{tabular}{|c|c|c|c|}
\hline & Home & Foreign & Total \\
\hline \hline Nash & $0.115913729 a^{2}$ & $0.231827458 a^{2}$ & $0.347741187 a^{2}$ \\
\hline Stackelberg (Home is leader) & $0.196888509 a^{2}$ & $0.131259006 a^{2}$ & $0.328147515 a^{2}$ \\
\hline
\end{tabular}

Table 6: Example 3 (stagewise solution): payoffs under $S_{0}=0, r=0.1$ and $c=1$ 


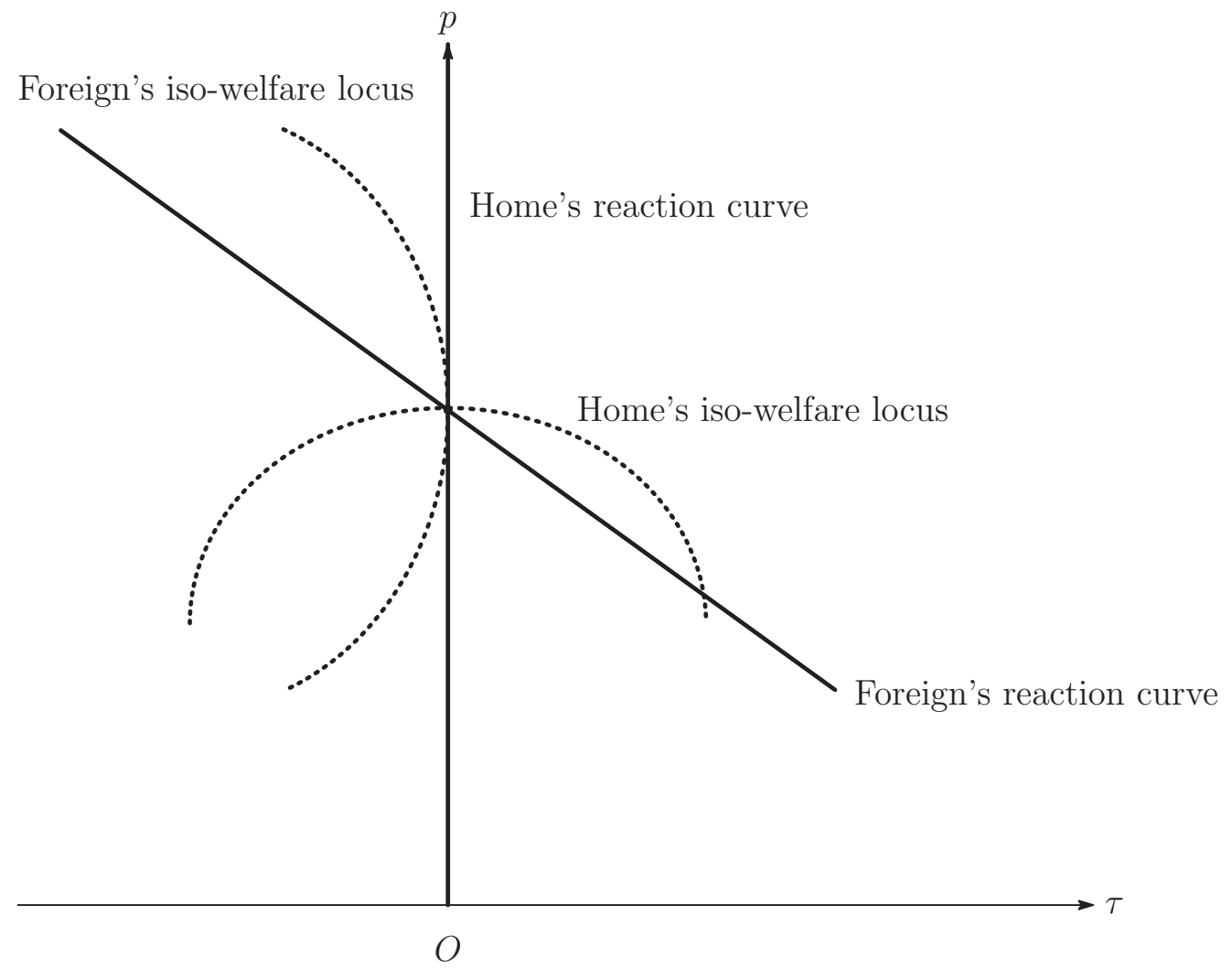

Figure 1: Reaction curves in the static model 